\title{
Biosurfactant-Producing Lactobacilli: Screening, Production Profiles, and Effect of Medium Composition
}

\author{
Eduardo J. Gudiña, José A. Teixeira, and Lígia R. Rodrigues \\ Institute for Biotechnology and Bioengineering (IBB), Centre of Biological Engineering, University of Minho, \\ Campus de Gualtar, 4710-057 Braga, Portugal \\ Correspondence should be addressed to Eduardo J. Gudiña, egudina@deb.uminho.pt
}

Received 22 June 2011; Accepted 28 September 2011

Academic Editor: Elena Tamburini

Copyright (๑) 2011 Eduardo J. Gudiña et al. This is an open access article distributed under the Creative Commons Attribution License, which permits unrestricted use, distribution, and reproduction in any medium, provided the original work is properly cited.

\begin{abstract}
Biosurfactant production was screened in four lactobacilli strains. The highest biosurfactant production (excreted and cellbound biosurfactants) was achieved with Lactobacillus paracasei ssp. paracasei A20, a strain isolated from a Portuguese dairy plant, with a decrease in the surface tension of $6.4 \mathrm{mN} \mathrm{m}^{-1}$ and $22.0 \mathrm{mN} \mathrm{m}^{-1}$, respectively. Biosurfactant production by this strain was evaluated under different culture broth compositions. The use of different nitrogen sources revealed that yeast extract is essential for bacterial growth, while peptone is crucial for biosurfactant synthesis. For biosurfactant production, the use of peptone and meat extract yielded a higher production when compared to the standard medium, with a surface tension reduction of $24.5 \mathrm{mN} \mathrm{m}^{-1}$. Furthermore, experiments were also conducted in a reactor with $\mathrm{pH}$ and temperature control. Biomass and biosurfactant production in bioreactor was higher comparing with the experiments conducted in shake flaks. The optimization procedure adopted in the current work was found to improve the biosurfactant production and opened new perspectives for the use of $L$. paracasei ssp. paracasei A20 as a promising biosurfactant-producer.
\end{abstract}

\section{Introduction}

Biosurfactants are surface-active compounds synthesized by microorganisms with pronounced surface and emulsifying activities $[1,2]$. Several properties and physiological functions in the producer organisms have been described for different groups of biosurfactants, that include solubility of hydrophobic compounds, heavy metal binding, bacterial pathogenesis, cell adhesion and aggregation, quorum sensing, and biofilm formation $[2,3]$.

Bacteria are the main group of biosurfactant-producing microorganisms, although they are also produced by some yeasts and filamentous fungi [4]. These compounds can be synthesized by microorganisms growing on water-immiscible hydrocarbons, as well as on water-soluble compounds such as glucose, sucrose, glycerol, or ethanol, and can be excreted or remain attached to the cell wall [5]. Diversity existing among the biosurfactant-producing microorganisms suggests that their production represents an important survival strategy and appears to have evolved in an independent, yet parallel fashion [6, 7]. A number of studies have reported the potential of lactobacilli as biosurfactantproducers [8-16]. Biosurfactants isolated from several lactobacilli have been characterized as multicomponent mixtures, consisting of protein and polysaccharides $[13,14,17,18]$; in other cases, the surface active compounds were identified as glycolipids $[8,12,15,16]$.

Comparing with chemical surfactants, these compounds have several advantages such as lower toxicity, higher biodegradability, and effectiveness at extreme temperatures and $\mathrm{pH}$ values $[2,4,5]$. Moreover, biosurfactants can be tailor-made to suit different applications by changing the production conditions, or by modifying the genes involved in their biosynthesis $[5,7]$. The diversity of biosurfactants makes them an attractive group of compounds for use in a wide variety of industrial and biotechnological applications such as agriculture, food production, chemistry, cosmetics, and pharmaceutics [1-5]. 
The use of biosurfactants represents an alternative and eco-friendly option for bioremediation technology in environments contaminated with hydrocarbons. Biosurfactants, which increase the surface area of hydrophobic waterinsoluble substrates, can be added to the bioremediation processes to stimulate the growth of oil-degrading bacteria and improve their ability to degrade hydrocarbons $[15,19]$.

Currently, the main factor that prevents the widespread use of biosurfactants is the process economics, and many strategies have been developed to reduce its production costs and make fermentation competitive with chemical synthesis [20]. The use of inexpensive substrates like agro-industrial wastes, medium and culture conditions optimization, development of efficient recovery process, and the engineering of the producer microorganisms can contribute to make their production more economically attractive through the development of cheaper and efficient processes [5, 20-27]. Future biosurfactant research should, therefore, be more focused on the economics of the production processes, particularly through the use of alternative low-cost fermentative media [20, 28].

The aims of this study were to screen a number of lactobacilli strains for biosurfactant production based on their ability to reduce surface tension and to determine the biosurfactant production profile for each strain. Additionally, for the best biosurfactant-producer, culture medium for growth and biosurfactant production was optimized.

\section{Materials and Methods}

2.1. Strains and Standard Culture Conditions. Four lactobacilli strains were investigated in this study. Lactobacillus coryniformis ssp. torquens CECT 25600 was obtained from the Spanish Collection of Type Cultures (Valencia, Spain); Lactobacillus paracasei ssp. paracasei A20, Lactobacillus plantarum A14, and Leuconostoc mesenteroides A4 were isolated from a Portuguese dairy plant.

Strains were stored at $-80^{\circ} \mathrm{C}$ in MRS broth (medium introduced by DeMan, Rogosa and Sharpe [29] for cultivation of Lactobacillus species (OXOID, Basingstoke, England)) containing $15 \%(\mathrm{v} / \mathrm{v})$ glycerol solution until use. Whenever required, frozen stocks were streaked on MRS agar plates and incubated overnight at the optimum growing temperature for each strain $\left(31^{\circ} \mathrm{C}\right.$ for L. mesenteroides $\mathrm{A} 4$ and $37^{\circ} \mathrm{C}$ for all the other strains) for further culturing. Working stock cultures were kept at $4^{\circ} \mathrm{C}$ for up to 2 weeks.

2.2. Growth Curves. The bacterial strains were cultured in shake flasks without baffles containing $100 \mathrm{~mL}$ MRS-Lac medium (standard MRS medium where glucose was replaced by lactose). To prepare subcultures, an individual colony was used to inoculate $10 \mathrm{~mL}$ of MRS-Lac broth for each strain. This preculture was incubated overnight under the optimal conditions, and $1 \mathrm{~mL}$ was used to inoculate a second culture of MRS-Lac broth $(100 \mathrm{~mL})$, which was grown for $72 \mathrm{~h}$, in ambient air at $31^{\circ} \mathrm{C}$ for L. mesenteroides $\mathrm{A} 4$ and $37^{\circ} \mathrm{C}$ for all the other strains. Samples were taken at different time points during the fermentation to determine biomass and lactose concentrations, as well as excreted biosurfactant production. The composition of MRS-Lac broth was $10.0 \mathrm{gL}^{-1}$ peptone, $8.0 \mathrm{gL}^{-1}$ meat extract, $4.0 \mathrm{gL}^{-1}$ yeast extract, $20.0 \mathrm{gL}^{-1}$ lactose, $2.0 \mathrm{gL}^{-1}$ di-potassium hydrogen phosphate, $5.0 \mathrm{gL}^{-1}$ sodium acetate $3 \mathrm{H}_{2} \mathrm{O} ; 2.0 \mathrm{gL}^{-1}$ tri-ammonium citrate, $0.2 \mathrm{gL}^{-1}$ magnesium sulfate $7 \mathrm{H}_{2} \mathrm{O}, 0.05 \mathrm{gL}^{-1}$ manganese sulfate $4 \mathrm{H}_{2} \mathrm{O}$, and $1.0 \mathrm{~mL}$ Tween 80 . The $\mathrm{pH}$ was adjusted to 6.2.

Bacterial growth was determined by measuring the optical density at $600 \mathrm{~nm}$ at different time intervals $(0,2,4$, $6,8,10,12,24,48$, and $72 \mathrm{~h}$ ), and biomass concentration ( $g$ dry weight $\mathrm{L}^{-1}$ ) was determined through a calibration curve for each strain. Lactose consumption was determined by measuring the reducing sugars in the culture broth supernatants using the DNS method as described by Miller [30].

2.3. Biosurfactant Recovery. Biosurfactants can be excreted or remain attached to the cell wall. In the last case, biosurfactants must be extracted from the cells, for example, with phosphate-buffered saline (PBS). The surface tension measured on the culture broth gives an indication of the excreted biosurfactant production, while the surface tension measured on the PBS extracts gives an indication of cellbound biosurfactant production. For excreted biosurfactant determination, at different time intervals samples were taken to assay the surface-activity of the culture broth supernatants.

For cell-bound biosurfactant determination, at the end of the experiments $(72 \mathrm{~h})$ cells were harvested by centrifugation $\left(10000 \times \mathrm{g}, 5 \mathrm{~min}, 10^{\circ} \mathrm{C}\right)$, washed twice in demineralized water, and resuspended in $20 \mathrm{~mL}$ of phosphate-buffered saline (PBS: $10 \mathrm{mM} \mathrm{KH} \mathrm{PO}_{4} / \mathrm{K}_{2} \mathrm{HPO}_{4}$ and $150 \mathrm{mM} \mathrm{NaCl}$ with $\mathrm{pH}$ adjusted to 7.0). The bacteria were left at room temperature up to $8 \mathrm{~h}$ with gentle stirring for biosurfactant release. During the extraction process, samples were taken at different time intervals $(0.5,2$, and $8 \mathrm{~h})$, bacteria were removed by centrifugation, and the remaining supernatant liquid was tested for surface-activity [11].

2.4. Surface-Activity Determination. The surface tension of the culture broth and PBS extracts samples was measured using the Ring method as previously described [31]. A KRÜSS K6 Tensiometer (KRÜSS GmbH, Hamburg, Germany) equipped with a $1.9 \mathrm{~cm}$ De Noüy platinum ring was used. Surface tension values represent an average of three independent measurements performed at room temperature $\left(20^{\circ} \mathrm{C}\right)$.

\subsection{Effect of Nitrogen Sources on Biosynthesis of Biosurfactant.} The influence of different nitrogen sources present in MRSLac broth (peptone, meat extract, and yeast extract) on L. paracasei ssp. paracasei A20 growth and biosurfactant production was evaluated by single factor design experiments in shake flasks. Nine different media were designed based on the MRS-Lac composition, changing the various nitrogen sources by the equivalent amount of ammonium and maintaining the total amount of nitrogen equal to the 
TABLE 1: Composition of the different culture media prepared replacing the nitrogen sources of MRS-Lac medium by ammonium. "D" corresponds to the standard MRS-Lac medium.

\begin{tabular}{|c|c|c|c|c|c|c|c|c|c|}
\hline \multirow{2}{*}{ Composition } & \multicolumn{9}{|c|}{ Medium } \\
\hline & A & B & $\mathrm{C}$ & $\mathrm{D}$ & E & $\mathrm{F}$ & G & $\mathrm{H}$ & I \\
\hline Peptone $\left(\mathrm{gL}^{-1}\right)$ & 10 & - & - & 10 & 10 & 10 & - & - & 10 \\
\hline Meat Extract $\left(\mathrm{gL}^{-1}\right)$ & - & 8 & - & 8 & 8 & - & 8 & - & 8 \\
\hline Yeast Extract $\left(\mathrm{gL}^{-1}\right)$ & - & - & 4 & 4 & - & 4 & 4 & - & 4 \\
\hline Ammonium $25 \%\left(\mathrm{~mL} \mathrm{l}^{-1}\right)$ & 7.4 & 8.9 & 12.1 & - & 2.1 & 5.3 & 6.8 & 14.2 & 14.2 \\
\hline
\end{tabular}

original medium. Table 1 summarizes the composition of the different media studied.

Growth curves were obtained for all the above mentioned media along the fermentation. Biomass production, lactose consumption, and surface tension reduction were determined at different time intervals. The cell-bound biosurfactant production was determined at the end of each experiment, as previously described.

2.6. Biosurfactant Production by L. paracasei ssp. paracasei A20 in Bioreactor. A 2-L reactor (Braun, Melsungen, Germany) equipped with agitation, temperature, and $\mathrm{pH}$ online measurement and control was used. Experiments were carried out at $37^{\circ} \mathrm{C}$ and $120 \mathrm{rpm}$ with $1-\mathrm{L}$ working volume. In the course of fermentation, $\mathrm{pH}$ was maintained at 6.2 by automatic addition of $6 \%(\mathrm{v} / \mathrm{v})$ ammonium and $21 \%(\mathrm{v} / \mathrm{v})$ ortophosphoric acid solutions. MRS-Lac broth and MRSLac with increasing concentrations of lactose (MRS-Lac II$50 \mathrm{gL}^{-1}$ and MRS-Lac III- $100 \mathrm{gL}^{-1}$ ) were used. Aeration was also studied in order to infer its effect in the biosurfactant production. Growth curves and cell-bound biosurfactant recovery were performed as previously described.

\section{Results and Discussion}

3.1. Screening of Lactobacilli for Biosurfactant Production. In this study, four lactobacilli strains were screened for cell-bound and excreted biosurfactant production. Growth curves were obtained for all the strains in order to establish the relationship between cell growth and biosurfactant production, since several different patterns have been described in various microorganisms $[4,11]$. A decrease in surface tension of the culture broth was observed for all strains after $72 \mathrm{~h}$ of culture, although those reductions varied markedly from 1.4 to $6.4 \mathrm{mN} \mathrm{m}^{-1}$ when compared to the surface tension of MRS-Lac broth $\left(53.0 \mathrm{mN} \mathrm{m}^{-1}\right)$ (Figure 1). From the small reductions detected in the surface tension of the culture broth supernatants during the fermentation, it can be concluded that the amount of biosurfactant excreted by these strains in those conditions was very low.

For all the studied strains, the excreted biosurfactant production was found to be growth-associated, as a parallel relationship could be observed between biomass production, lactose consumption, and the decrease in the culture broth surface tension (Figure 1). As expected from this biosurfactant production profile, the lowest values of surface tension were obtained at the end of the fermentation. L. paracasei ssp. paracasei A20 showed the highest excreted biosurfactant production rate, with a reduction in the culture broth surface tension of $6.4 \mathrm{mN} \mathrm{m}^{-1}$.

Velraeds and collaborators [14] showed that biosurfactant release by different lactobacilli strains is maximal for cells in the stationary growth phase. Rodrigues et al. [11] observed that biosurfactant production by lactobacilli occurs mainly in the first 4 hours of culture, when cell growth is almost inexistent and the substrate consumption is very low. However, biosurfactant production continues during all the fermentation, although at a slower rate.

Table 2 compiles the surface tension values obtained during the PBS extraction procedure used to recover the cellbound biosurfactants. Results showed that a $2 \mathrm{~h}$ extraction time at room temperature is enough to recover the cellbound biosurfactants produced. Longer extraction times do not represent an advantage, since no further significant decrease in the surface tension could be obtained. This observation is in accordance with previously reported studies for other lactobacilli [11]. Thus, from this moment on, the time used to extract the cell-bound biosurfactants was established as $2 \mathrm{~h}$. L. paracasei ssp. paracasei A20 was found to produce the highest cell-bound biosurfactant levels, with a reduction in surface tension of $22.0 \mathrm{mN} \mathrm{m}^{-1}$ as compared to PBS (control).

For all the studied strains, the levels of cell-bound biosurfactant production were found to be higher than the excreted ones, as it was previously described for other lactobacilli $[11,13,14]$. On the contrary, other microorganisms (such as Bacillus and Pseudomonas species) produce mainly excreted biosurfactants, which are secreted into the medium, leading to substantial decreases in its surface tension [32]. Velraeds and coworkers [14] studied 15 Lactobacillus strains and reported surface tension reductions after PBS extraction between 12.0 and $29.0 \mathrm{mN} \mathrm{m}^{-1}$. In the same way, Rodrigues et al. [11] obtained surface tension reductions between 17.0 and $21.5 \mathrm{mN} \mathrm{m}^{-1}$ using other Lactobacillus strains. Therefore, the results obtained for $L$. paracasei ssp. paracasei A20 in the current work are in accordance with the previously reported data for other lactobacilli.

Busscher and collaborators [33] established a minimum decrease in surface tension as $8 \mathrm{mN} \mathrm{m}^{-1}$ to distinguish between biosurfactant producing and nonproducing organisms. Taking into account this value, none of the studied lactobacilli strains could be considered as an excreted biosurfactant producer. Furthermore, regarding the cellbound biosurfactant production, the strains $L$. coryniformis 


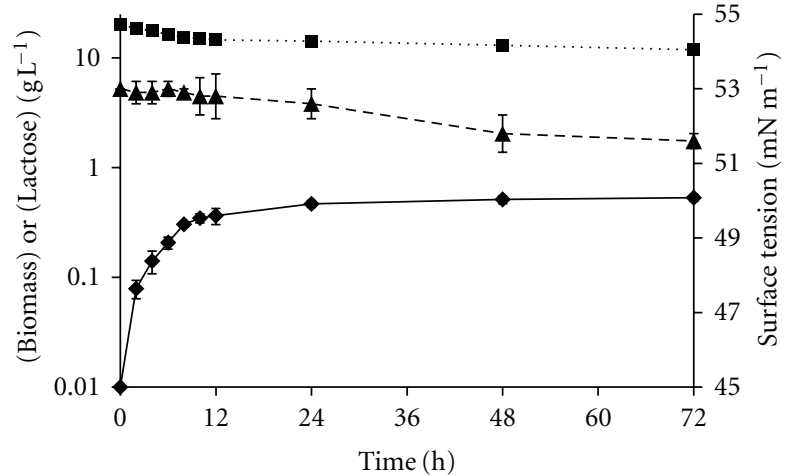

(a)

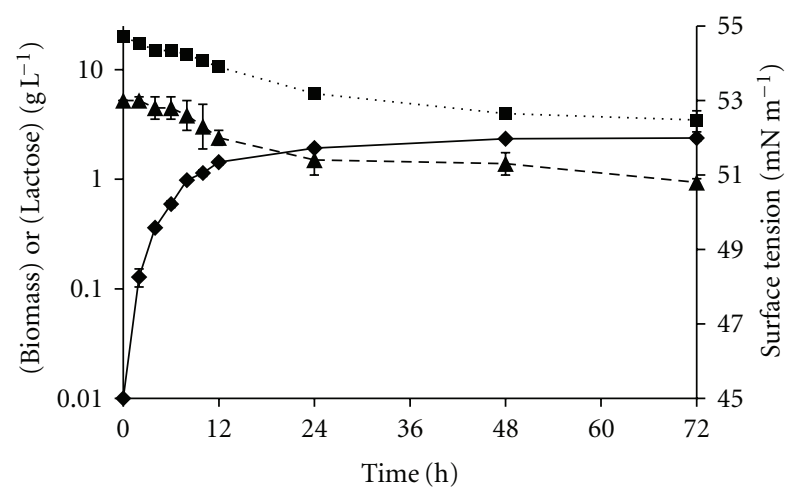

(c)

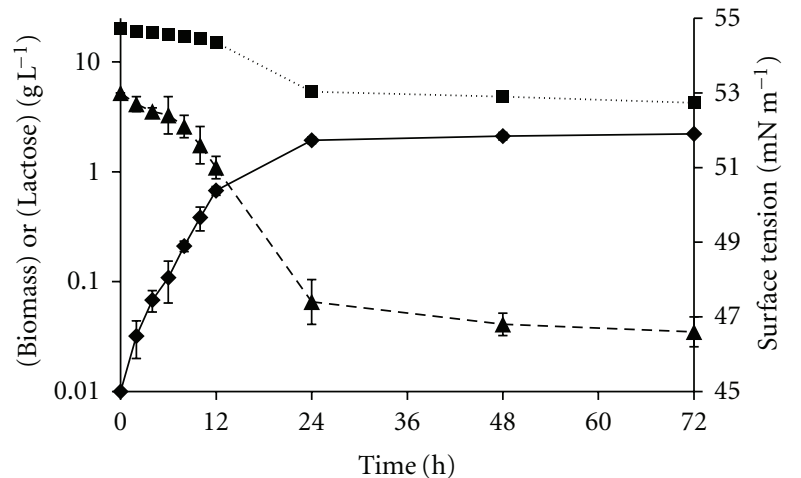

(b)

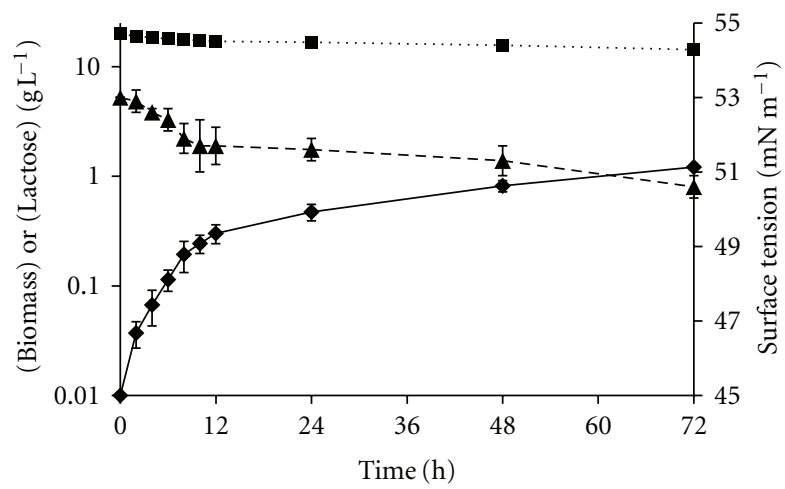

(d)

FIGURE 1: Extracellular surface tension variation, biomass, and lactose concentrations obtained from fermentations carried out in shake flasks with MRS-Lac broth using (a) L. coryniformis ssp. torquens CECT 25600, (b) L. paracasei ssp. paracasei A20, (c) L. plantarum A14, and (d) L. mesenteroides A4. Results represent the average of three independent experiments. (Biomass): - - ; (Lactose): -- $--;$ Surface Tension: -A-.

TABLE 2: Surface tension values $\left(\mathrm{mN} \mathrm{m}^{-1}\right)$ obtained from the biosurfactant extraction with PBS for the different strains during $8 \mathrm{~h}$ (the control surface tension (PBS) was $72.0 \mathrm{mN} \mathrm{m}^{-1}$ ). Results are expressed as means \pm standard deviations of values from triplicate experiments.

\begin{tabular}{|c|c|c|c|c|}
\hline \multirow{2}{*}{ Strain } & \multicolumn{4}{|c|}{ Surface Tension $\left(\mathrm{mN} \mathrm{m}^{-1}\right)$} \\
\hline & $0 \mathrm{~h}$ & $0.5 \mathrm{~h}$ & $2 \mathrm{~h}$ & $8 \mathrm{~h}$ \\
\hline Lactobacillus coryniformis ssp. torquens CECT 25600 & $72.0 \pm 0.1$ & $70.3 \pm 0.6$ & $68.1 \pm 0.5$ & $67.0 \pm 0.4$ \\
\hline Lactobacillus paracasei ssp. paracasei A20 & $72.0 \pm 0.1$ & $51.4 \pm 0.4$ & $50.2 \pm 0.3$ & $50.0 \pm 0.4$ \\
\hline Lactobacillus plantarum A14 & $72.0 \pm 0.1$ & $60.7 \pm 0.5$ & $60.6 \pm 0.6$ & $59.9 \pm 0.4$ \\
\hline Leuconostoc mesenteroides A4 & $72.0 \pm 0.1$ & $70.8 \pm 0.3$ & $69.7 \pm 0.4$ & $69.6 \pm 0.4$ \\
\hline
\end{tabular}

ssp. torquens CECT 25600 and L. mesenteroides A4 were also considered as nonproducers. In view of the results gathered in both Figure 1 and Table 2, L. paracasei ssp. paracasei A20 was found to be the strain with the highest potential of biosurfactant production. Therefore, the optimization of the culture medium composition for both biomass growth and biosurfactant production by this strain was further pursued.

3.2. Effect of Nitrogen Sources on the Biosynthesis of Biosurfactant by L. paracasei ssp. paracasei A20. As described in Table 1, several media were used to study the biosurfactant production by L. paracasei ssp. paracasei A20. Results from these experiments are shown in Table 3. The first conclusion that can be drawn is that the ammonium concentrations used do not represent any negative effect for this strain, since medium I, which composition is the same as for medium D (MRS-Lac) but supplemented with the highest ammonium concentration studied $\left(14.2 \mathrm{~mL} \mathrm{l}^{-1}\right)$, yields a higher biomass production than medium $\mathrm{D}$, and a similar biosurfactant production. However, it was found that when all the nitrogen sources are replaced by the equivalent amount of ammonium (medium $\mathrm{H}$ ), there is no growth, probably due to the lack of some essential nutrients. Therefore, the presence of at least one conventional nitrogen source is necessary for growth.

Lactic acid bacteria (LAB) are extremely fastidious microorganisms adapted to complex organic substrates. These bacteria require not only carbohydrates as energy and carbon sources but also nucleotides, amino acids, peptides, vitamins, 
TABLE 3: Biomass concentrations ( $\mathrm{g}$ dry weight $\mathrm{l}^{-1}$ ), biomass percentages (as compared to medium $\mathrm{D}$ that was set to be $100 \%$ ), and surface tension reductions $\left(\mathrm{mN} \mathrm{m}^{-1}\right)$ in the culture broth supernatants (excreted biosurfactant) and for the PBS extracted solutions (cell-bound biosurfactant), obtained for L. paracasei ssp. paracasei A20 grown in the different culture media at $72 \mathrm{~h}$ of culture. Results represent the average of three independent experiments \pm standard deviation.

\begin{tabular}{lcccc}
\hline Medium & $\begin{array}{c}\text { (Biomass) } \\
\left(\mathrm{gL}^{-1}\right)\end{array}$ & $\begin{array}{c}\text { \% (w/w) } \\
\text { Biomass }\end{array}$ & $\begin{array}{c}\text { Reduction of culture broth surface tension } \\
\left(\mathrm{mN} \mathrm{m}^{-1}\right)\end{array}$ & $\begin{array}{c}\text { Reduction of PBS surface tension } \\
\left(\mathrm{mN} \mathrm{m}^{-1}\right)\end{array}$ \\
\hline A & 0.378 & 15.5 & $3.5 \pm 0.4$ & $16.7 \pm 0.7$ \\
B & 0.669 & 27.4 & $2.1 \pm 0.4$ & $15.3 \pm 0.6$ \\
C & 1.959 & 80.1 & $3.6 \pm 0.4$ & $16.8 \pm 0.5$ \\
D & 2.446 & 100.0 & $6.4 \pm 0.2$ & $21.8 \pm 0.4$ \\
E & 1.847 & 75.5 & $8.0 \pm 0.3$ & $24.5 \pm 0.4$ \\
F & 2.294 & 93.8 & $7.9 \pm 0.4$ & $24.3 \pm 0.5$ \\
G & 2.327 & 95.1 & $3.5 \pm 0.3$ & $16.8 \pm 0.4$ \\
H & 0.094 & 3.8 & $0.6 \pm 0.2$ & - \\
I & 2.805 & 114.7 & $6.4 \pm 0.3$ & $21.7 \pm 0.3$ \\
\hline
\end{tabular}

and minerals for growth, due to the lack of various biosynthetic pathways. For instance, LAB are unable of growing at the expense of mineral nitrogen in the absence of exogenous amino acids [34], and their nutritional requirements are usually satisfied in complex growth media by the addition of undefined and expensive compounds such as peptone, meat extract, and yeast extract [29].

The results obtained with media that contain two nitrogen sources (E, F, G) clearly showed that yeast extract is the most important factor for bacterial growth and followed by meat extract, whereas peptone seems to be the least important factor. Regarding the media which contain only one nitrogen source $(\mathrm{A}, \mathrm{B}, \mathrm{C})$ the same conclusions could be drawn. Biomass concentrations varied markedly from 0.378 to $2.805 \mathrm{gL}^{-1}$ for the different media studied. As for biosurfactant production, it seems that peptone is the most important component despite its small contribution for biomass production. The highest cell-bound and excreted biosurfactant productions were obtained using media $\mathrm{E}$ and F (both of them containing peptone). Both media yielded higher amounts of biosurfactant than medium $\mathrm{D}$, whereas all the other media resulted in lower amounts. Interestingly, biomass production with media $\mathrm{E}$ and $\mathrm{F}$ is lower than that with medium $\mathrm{D}$ (Table 3 ), although biosurfactant production is higher. With medium $\mathrm{E}$, a surface tension reduction in the culture broth of $8.0 \mathrm{mN} \mathrm{m}^{-1}$, and $24.5 \mathrm{mN} \mathrm{m}^{-1}$ in the PBS extracts, was obtained. Thus, this medium was chosen to be used in the following optimization studies.

For all the media evaluated, excreted biosurfactant production by $L$. paracasei ssp. paracasei A20 was found to be growth-associated, as it was previously described for MRS-Lac (Figure 2). However, comparing the results for the different media, it was found that a higher biomass production does not always result in a higher biosurfactant yield (Table 3). This observation is in accordance with previous reports described in the literature, since the relationship between biomass and biosurfactant production depends largely on the medium composition, and the carbon and nitrogen sources are key players for the regulation of biosurfactants synthesis $[11,27,35,36]$. For microorganisms exhibiting a growth-associated biosurfactant production, the use of different carbon and nitrogen sources can promote growth without biosurfactant production. In addition, the different substrates used not only influence the amount of biosurfactant produced but can also result in the synthesis of products with different composition and properties [7]. For example, in Bacillus circulans the biosurfactant production is growth-associated; however, the carbon source used affects biosurfactant production qualitatively and quantitatively, even changing the biosurfactant antimicrobial properties [37]. A similar effect has been described in Pseudomonas fluorescens regarding the carbon and nitrogen sources as well as the $\mathrm{C}: \mathrm{N}$ ratio [35].

3.3. Biosurfactant Production in Reactor. Growth and biosurfactant production by $L$. paracasei ssp. paracasei A20 were also studied using a bioreactor in order to further optimize the process. In these experiments, $\mathrm{pH}$ was maintained constant at its optimum value (6.2) through all the fermentation. $\mathrm{pH}$ is one of the most important parameters affecting cell growth and metabolism. LAB produce large amounts of lactic acid, which results in a marked $\mathrm{pH}$ decrease along the fermentation. In the current study, for the experiments conducted in shake flasks the $\mathrm{pH}$ of the culture broth decreased from 6.2 to values around 3.5. As a result of those low $\mathrm{pH}$ values, growth and biosurfactant production are inhibited.

A first experiment was conducted without aeration using MRS-Lac as the culture broth. The carbon source was exhausted at 24 hours of culture resulting in cell death. Biomass concentration of $2.1 \mathrm{gL}^{-1}$ and culture broth and PBS surface tension reductions of $3.5 \mathrm{~m} \mathrm{~m}^{-1}$ and $14.5 \mathrm{mN} \mathrm{m}^{-1}$, respectively, were obtained (Table 4). The rapid lactose depletion must be due to the $\mathrm{pH}$ control at its optimum value, which allows a faster growth as compared with experiments in shake flasks. Therefore, in order to avoid this effect, the lactose concentration was increased to $50 \mathrm{gL}^{-1}$ (MRS-Lac II) and $100 \mathrm{gL}^{-1}$ (MRS-Lac III) with the respective adjustment of the nitrogen sources to maintain the ratio $\mathrm{C} / \mathrm{N}$ invariable. When those media were assayed in bioreactor, lactose starvation 


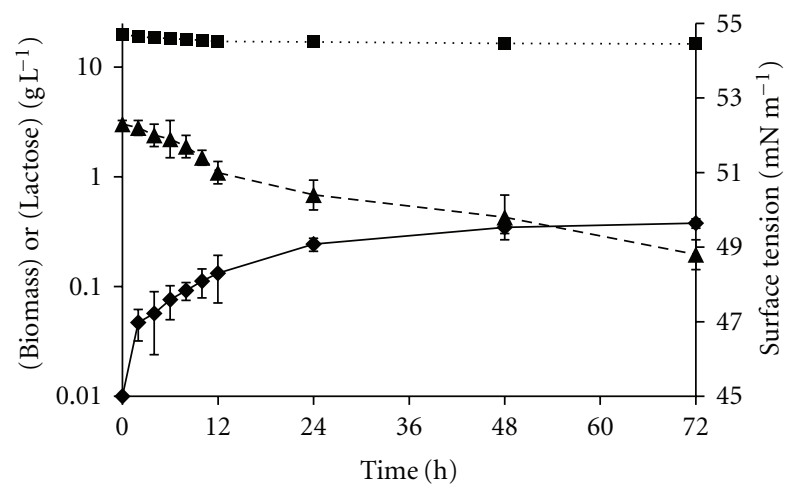

(a)

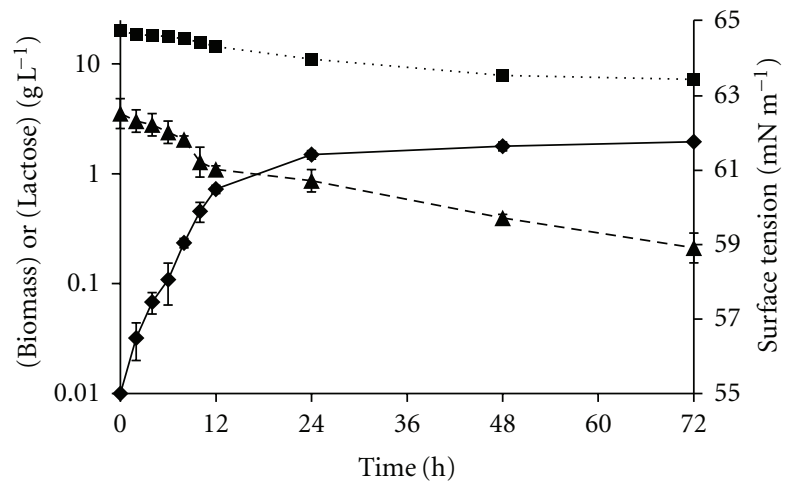

(c)

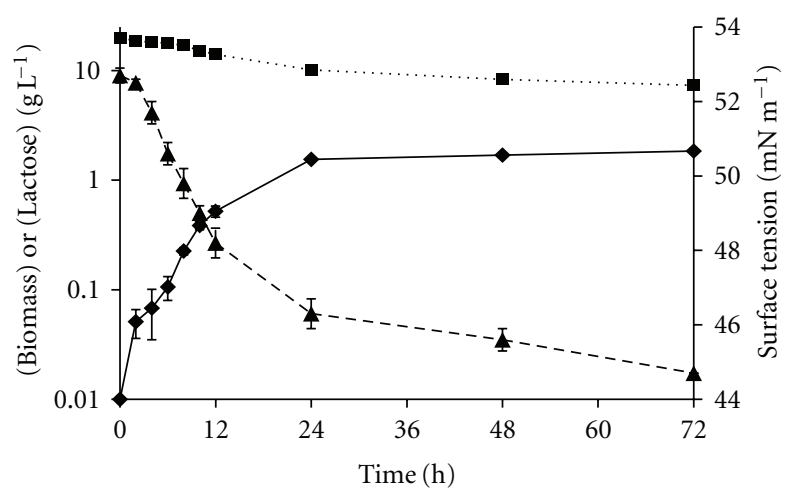

(e)

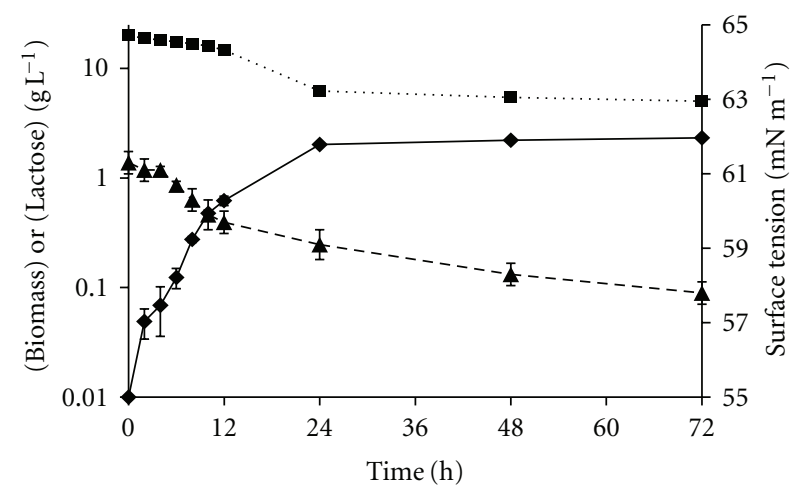

(g)

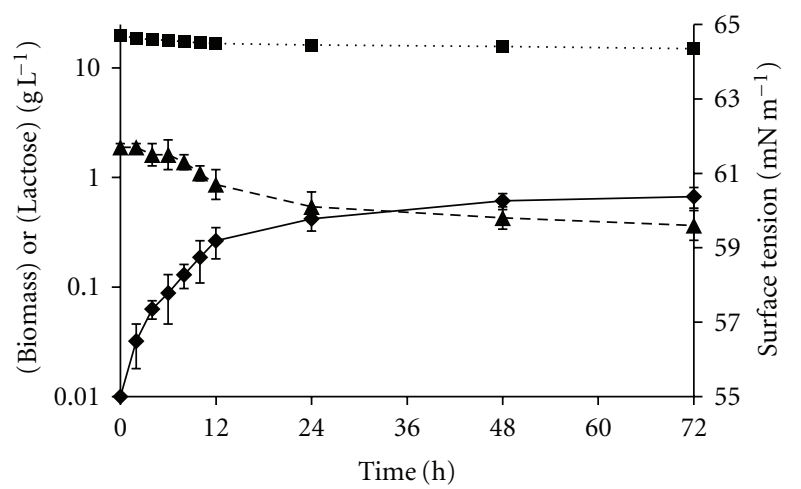

(b)

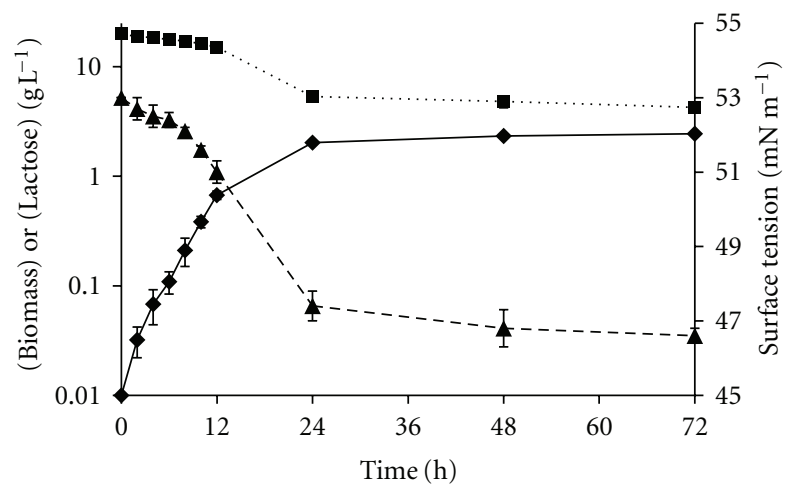

(d)

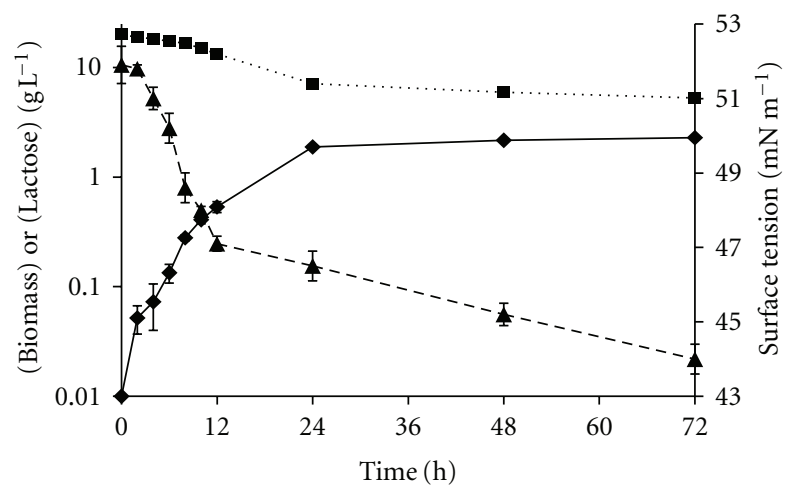

(f)

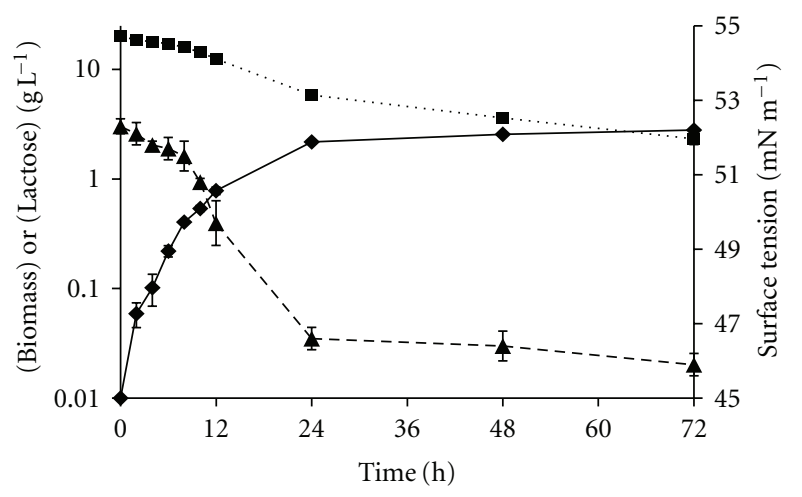

(h)

FIGURE 2: Representation of the extracellular surface tension variations and biomass and lactose concentrations obtained from fermentations carried out with L. paracasei ssp. paracasei A20 in shake flasks with the different media derived from MRS-Lac broth (A-H) as described in Table 1. Results represent the average of three independent experiments. (Biomass): - - ; (Lactose): -- -- ; Surface Tension: $-\mathbf{\Delta}-$. 
TABLE 4: Biomass concentrations $\left(\mathrm{gL}^{-1}\right)$ and surface tension reductions $\left(\mathrm{mN} \mathrm{m}^{-1}\right)$ obtained for L. paracasei ssp. paracasei A20 supernatants

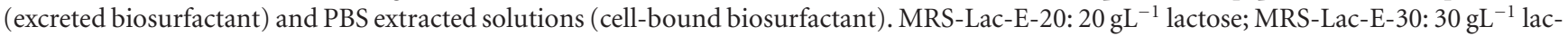
tose; MRS-Lac-E-40: $40 \mathrm{gL}^{-1}$ lactose; and MRS-Lac-E-50: $50 \mathrm{gL}^{-1}$ lactose. Results represent the average of three independent experiments \pm standard deviation.

\begin{tabular}{|c|c|c|c|}
\hline & $\begin{array}{l}\text { Reduction of culture broth surface tension } \\
\qquad\left(\mathrm{mN} \mathrm{m}^{-1}\right)\end{array}$ & $\begin{array}{l}\text { Reduction of PBS surface tension } \\
\qquad\left(\mathrm{mN} \mathrm{m}^{-1}\right)\end{array}$ & $\begin{array}{c}\text { Biomass } \\
\left(\mathrm{gL}^{-1}\right)\end{array}$ \\
\hline \multicolumn{4}{|l|}{ Flask } \\
\hline MRS-Lac & $6.4 \pm 0.4$ & $21.8 \pm 0.4$ & 2.446 \\
\hline \multicolumn{4}{|c|}{ Reactor (without aeration) } \\
\hline MRS-Lac & $3.5 \pm 0.5$ & $14.5 \pm 0.6$ & 2.100 \\
\hline MRS-Lac II & $6.4 \pm 0.2$ & $22.5 \pm 0.4$ & 3.478 \\
\hline MRS-Lac III & $6.0 \pm 0.5$ & $22.0 \pm 0.1$ & 3.408 \\
\hline MRS-Lac-E-20 & $3.6 \pm 0.2$ & $14.3 \pm 0.3$ & 1.243 \\
\hline MRS-Lac-E-30 & $5.2 \pm 0.3$ & $18.5 \pm 0.6$ & 2.056 \\
\hline MRS-Lac-E-40 & $6.6 \pm 0.7$ & $21.7 \pm 0.5$ & 2.867 \\
\hline MRS-Lac-E-50 & $7.8 \pm 0.4$ & $24.7 \pm 0.3$ & 3.328 \\
\hline \multicolumn{4}{|c|}{ Reactor (with aeration) } \\
\hline MRS-Lac II & $5.9 \pm 0.5$ & $18.9 \pm 0.1$ & 4.170 \\
\hline
\end{tabular}

was not observed, and biomass and biosurfactant production were higher comparing to the data obtained for MRS-Lac (Table 4). Furthermore, as expected it can be observed that biomass and biosurfactant production values obtained in bioreactor were higher than the ones obtained in shake flasks. MRS-Lac III did not yield better results than MRS-Lac II, probably due to an inhibitory effect of the carbon source (Table 4). In view of these results, MRS-Lac II was selected as the most favorable medium for growth and biosurfactant production in bioreactor.

Biosurfactant production in some yeast is stimulated when the agitation and aeration rates are increased [32]. In $\mathrm{LAB}$, the citric acid cycle or a respiratory chain does not exist; however these bacteria are able to grow in the presence of oxygen due to the activity of oxygen-metabolizing enzymes such as superoxide dismutases, NADH oxidases, and NADH peroxidases. To evaluate the effect that aeration displays in cellular growth and biosurfactant production, another assay was carried out in bioreactor using MRS-Lac II as the culture broth, but maintaining a $20 \%(\mathrm{v} / \mathrm{v})$ oxygen concentration. In this case, biomass concentration was higher than in the experiment conducted without aeration, whereas the biosurfactant production was found to be lower (Table 4). Therefore, regarding biosurfactant production using this strain, and comparing all the results obtained in bioreactor, growth without aeration yielded better results than that with aeration.

Previous studies demonstrated that MRS-Lac-E was the most favorable medium for biosurfactant production by $L$. paracasei ssp. paracasei A20 in shake flasks (Table 3 and Figure 2(e)). Therefore, in order to further optimize this medium, and as prior results showed that higher lactose concentrations result in higher biomass and biosurfactant yields in bioreactor, several media with different lactose concentrations were studied using the same operational conditions earlier described (without aeration) (Table 4). The results showed that increasing lactose concentrations conduct to an increase in the biomass concentration (from 1.243 to $3.328 \mathrm{gL}^{-1}$ ). Furthermore, as previously observed in shake flasks, using the same lactose concentration $\left(50 \mathrm{gL}^{-1}\right)$, the biomass concentration with MRS-Lac-E-50 in bioreactor was lower than that with MRS-Lac II, thus confirming that yeast extract is an important factor for the growth of this strain. As for the biosurfactant production, the increase of lactose concentration conducted to a more pronounced synthesis of cell-bound and excreted biosurfactants (Table 4). The best result was obtained for medium MRS-Lac-E-50, with surface tension reductions of $7.8 \mathrm{mN} \mathrm{m}^{-1}$ in the culture broth, and $24.7 \mathrm{mN} \mathrm{m}^{-1}$ in PBS extracts.

\section{Conclusions}

Although lactobacilli produce lower amounts of biosurfactants when compared with other microorganisms, such as Bacillus subtilis or Pseudomonas aeruginosa, and exhibit many nutritional requirements, they constitute a promising source of biosurfactants, because these microorganisms are usually considered GRAS and are already used in many food manufacturing and industrial process. Furthermore, an increase in biosurfactant production yields can be achieved through the optimization of the culture conditions. In this study, a biosurfactant-producing strain was isolated from a Portuguese dairy plant, and the effect of different nitrogen sources on growth and biosurfactant production was evaluated. Yeast extract was found to be an essential component for bacterial growth, while peptone is the most important factor for biosurfactant production. Combination of peptone and meat extract resulted in a higher biosurfactant production when compared to the standard medium. As a result of the optimization process, biosurfactant production was improved, both in flask and in reactor, which opens the possibility for using $L$. paracasei ssp. paracasei A20 as a promising biosurfactant-producer. 


\section{Acknowledgment}

This work was supported by FCT (Portugal) under the scope of the Project BIOSURFA: Biosurfactants application for microbial adhesion inhibition in medical devices (PTDC/ SAU-BEB/73498/2006).

\section{References}

[1] L. R. Rodrigues, I. M. Banat, J. A. Teixeira, and R. Oliveira, "Biosurfactants: potential applications in medicine," Journal of Antimicrobial Chemotherapy, vol. 57, no. 4, pp. 609-618, 2006.

[2] J. D. Van Hamme, A. Singh, and O. P. Ward, "Physiological aspects. Part 1 in a series of papers devoted to surfactants in microbiology and biotechnology," Biotechnology Advances, vol. 24, no. 6, pp. 604-620, 2006.

[3] P. Singh and S. S. Cameotra, "Potential applications of microbial surfactants in biomedical sciences," Trends in Biotechnology, vol. 22, no. 3, pp. 142-146, 2004.

[4] J. D. Desai and I. M. Banat, "Microbial production of surfactants and their commercial potential," Microbiology and Molecular Biology Reviews, vol. 61, no. 1, pp. 47-64, 1997.

[5] S. Mukherjee, P. Das, and R. Sen, "Towards commercial production of microbial surfactants," Trends in Biotechnology, vol. 24, no. 11, pp. 509-515, 2006.

[6] A. A. Bodour, K. P. Drees, and R. M. Maier, "Distribution of biosurfactant-producing bacteria in undisturbed and contaminated arid southwestern soils," Applied and Environmental Microbiology, vol. 69, no. 6, pp. 3280-3287, 2003.

[7] O. Langer, O. Palme, V. Wray, H. Tokuda, and S. Lang, "Production and modification of bioactive biosurfactants," Process Biochemistry, vol. 41, no. 10, pp. 2138-2145, 2006.

[8] H. J. Busscher, C. G. Van Hoogmoed, G. I. GeertsemaDoornbusch, M. Van Der Kuijl-Booij, and H. C. Van Der Mei, "Streptococcus thermophilus and its biosurfactants inhibit adhesion by Candida spp. on silicone rubber," Applied and Environmental Microbiology, vol. 63, no. 10, pp. 3810-3817, 1997.

[9] E. J. Gudiña, V. Rocha, J. A. Teixeira, and L. R. Rodrigues, "Antimicrobial and antiadhesive properties of a biosurfactant isolated from Lactobacillus paracasei ssp. paracasei A20," Letters in Applied Microbiology, vol. 50, no. 4, pp. 419-424, 2010.

[10] E. J. Gudiña, J. A. Teixeira, and L. R. Rodrigues, "Isolation and functional characterization of a biosurfactant produced by Lactobacillus paracasei," Colloids and Surfaces B, vol. 76, no. 1, pp. 298-304, 2010.

[11] L. R. Rodrigues, A. Moldes, J. A. Teixeira, and R. Oliveira, "Kinetic study of fermentative biosurfactant production by Lactobacillus strains," Biochemical Engineering Journal, vol. 28, no. 2, pp. 109-116, 2006.

[12] C. G. Van Hoogmoed, M. Van Der Kuijl-Booij, H. C. Van Der Mei, and H. J. Busscher, "Inhibition of Streptococcus mutans NS adhesion to glass with and without a salivary conditioning film by biosurfactant-releasing Streptococcus mitis strains," Applied and Environmental Microbiology, vol. 66, no. 2, pp. 659-663, 2000.

[13] M. M. Velraeds, H. C. Van der Mei, G. Reid, and H. J. Busscher, "Physicochemical and biochemical characterization of biosurfactants released by Lactobacillus strains," Colloids and Surfaces B, vol. 8, no. 1-2, pp. 51-61, 1996.

[14] M. M. Velraeds, H. C. Van der Mei, G. Reid, and H. J. Busscher, "Inhibition of initial adhesion of uropathogenic Enterococcus faecalis by biosurfactants from Lactobacillus isolates," Applied and Environmental Microbiology, vol. 62, no. 6, pp. 1958-1963, 1996.

[15] R. Thavasi, S. Jayalakshmi, and I. M. Banat, "Application of biosurfactant produced from peanut oil cake by Lactobacillus delbrueckii in biodegradation of crude oil," Bioresource Technology, vol. 102, no. 3, pp. 3366-3372, 2011.

[16] P. Saravanakumari and K. Mani, "Structural characterization of a novel xylolipid biosurfactant from Lactococcus lactis and analysis of antibacterial activity against multi-drug resistant pathogens," Bioresource Technology, vol. 101, no. 22, pp. 88518854, 2010.

[17] L. R. Rodrigues, J. A. Teixeira, H. C. van der Mei, and R. Oliveira, "Isolation and partial characterization of a biosurfactant produced by Streptococcus thermophilus A," Colloids and Surfaces B, vol. 53, no. 1, pp. 105-112, 2006.

[18] L. R. Rodrigues, J. A. Teixeira, H. C. van der Mei, and R. Oliveira, "Physicochemical and functional characterization of a biosurfactant produced by Lactococcus lactis 53," Colloids and Surfaces B, vol. 49, no. 1, pp. 79-86, 2006.

[19] M. Pacwa-Plociniczak, G. A. Plaza, Z. Piotrowska-Seget, and S. S. Cameotra, "Environmental applications of biosurfactants: recent advances," International Journal of Molecular Sciences, vol. 12, pp. 633-654, 2011.

[20] R. S. Makkar and S. S. Cameotra, "An update on the use of unconventional substrates for biosurfactant production and their new applications," Applied Microbiology and Biotechnology, vol. 58, no. 4, pp. 428-434, 2002.

[21] F. F. Barros, A. N. Ponezi, and G. M. Pastore, "Production of biosurfactant by Bacillus subtilis LB5a on a pilot scale using cassava wastewater as substrate," Journal of Industrial Microbiology and Biotechnology, vol. 35, no. 9, pp. 1071-1078, 2008.

[22] G. Bustos, N. de la Torre, A. B. Moldes, J. M. Cruz, and J. M. Domínguez, "Revalorization of hemicellulosic trimming vine shoots hydrolyzates trough continuous production of lactic acid and biosurfactants by L. pentosus," Journal of Food Engineering, vol. 78, no. 2, pp. 405-412, 2007.

[23] S. Fox and G. Bala, "Production of surfactant from Bacillus subtilis ATCC 21332 using potato substrates," Bioresource Technology, vol. 75, no. 3, pp. 235-240, 2000.

[24] S. Joshi, C. Bharucha, S. Jha, S. Yadav, A. Nerurkar, and A. J. Desai, "Biosurfactant production using molasses and whey under thermophilic conditions," Bioresource Technology, vol. 99, no. 1, pp. 195-199, 2008.

[25] A. B. Moldes, A. M. Torrado, M. T. Barral, and J. M. Dominguez, "Evaluation of biosurfactant production from various agricultural residues by Lactobacillus pentosus," Journal of Agricultural and Food Chemistry, vol. 55, no. 11, pp. 44814486, 2007.

[26] O. M. P. Rivera, A. B. Moldes, A. M. Torrado, and J. M. Domínguez, "Lactic acid and biosurfactants production from hydrolyzed distilled grape marc," Process Biochemistry, vol. 42, no. 6, pp. 1010-1020, 2007.

[27] L. R. Rodrigues, J. A. Teixeira, and R. Oliveira, "Low-cost fermentative medium for biosurfactant production by probiotic bacteria," Biochemical Engineering Journal, vol. 32, no. 3, pp. 135-142, 2006.

[28] L. R. Rodrigues and J. A. Teixeira, "Biosurfactants production from cheese whey," in Advances in Cheese Whey Utilization, M. E. Cerdán, M. González-Siso, and M. Becerra, Eds., pp. 81104, Transworld Research Network, 2008.

[29] J. C. DeMan, M. Rogosa, and M. E. Sharpe, "A medium for the cultivation of lactobacilli," Journal of Applied Bacteriology, vol. 23, pp. 130-135, 1960. 
[30] G. L. Miller, "Use of dinitrosalicylic acid reagent for determination of reducing sugar," Analytical Chemistry, vol. 31, no. 3, pp. 426-428, 1959.

[31] S. Kim, E. Lim, S. Lee, J. Lee, and T. Lee, "Purification and characterization of biosurfactants from Nocardia sp. L-417," Biotechnology and Applied Biochemistry, vol. 31, no. 3, pp. 249253, 2000.

[32] G. Georgiou, S. C. Lin, and M. M. Sharma, "Surface-active compounds from microorganisms," Biotechnology, vol. 10, no. 1, pp. 60-65, 1992.

[33] H. J. Busscher, T. Neu, and H. C. Van der Mei, "Biosurfactant production by thermophilic dairy streptococci," Applied Microbiology and Biotechnology, vol. 41, no. 1, pp. 4-7, 1994.

[34] T. Morishita, Y. Deguchi, and M. Yajima, "Multiple nutritional requirements of lactobacilli: genetic lesions affecting amino acid biosynthetic pathways," Journal of Bacteriology, vol. 148, no. 1, pp. 64-71, 1981.

[35] M. Abouseoud, R. Maachi, A. Amrane, S. Boudergua, and A. Nabi, "Evaluation of different carbon and nitrogen sources in production of biosurfactant by Pseudomonas fluorescens," Desalination, vol. 223, no. 1-3, pp. 143-151, 2008.

[36] L. R. Rodrigues, J. A. Teixeira, R. Oliveira, and H. C. Van der Mei, "Response surface optimization of the medium components for the production of biosurfactants by probiotic bacteria," Process Biochemistry, vol. 41, no. 1, pp. 1-10, 2006.

[37] P. Das, S. Mukherjee, and R. Sen, "Substrate dependent production of extracellular biosurfactant by a marine bacterium," Bioresource Technology, vol. 100, no. 2, pp. 1015-1019, 2009. 

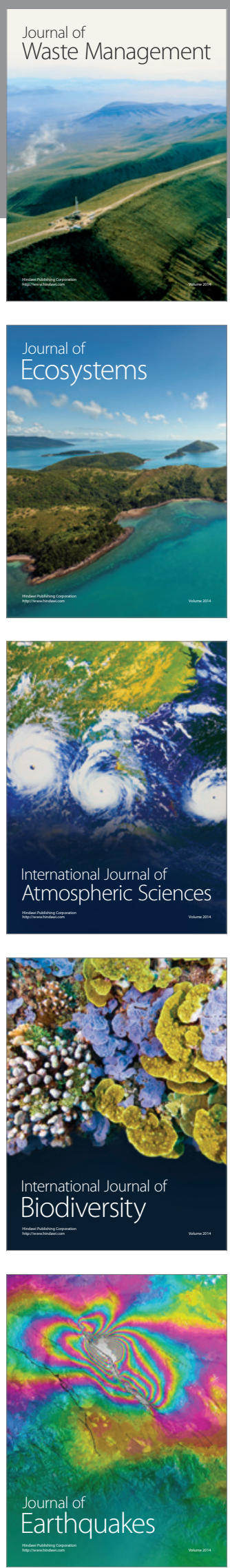
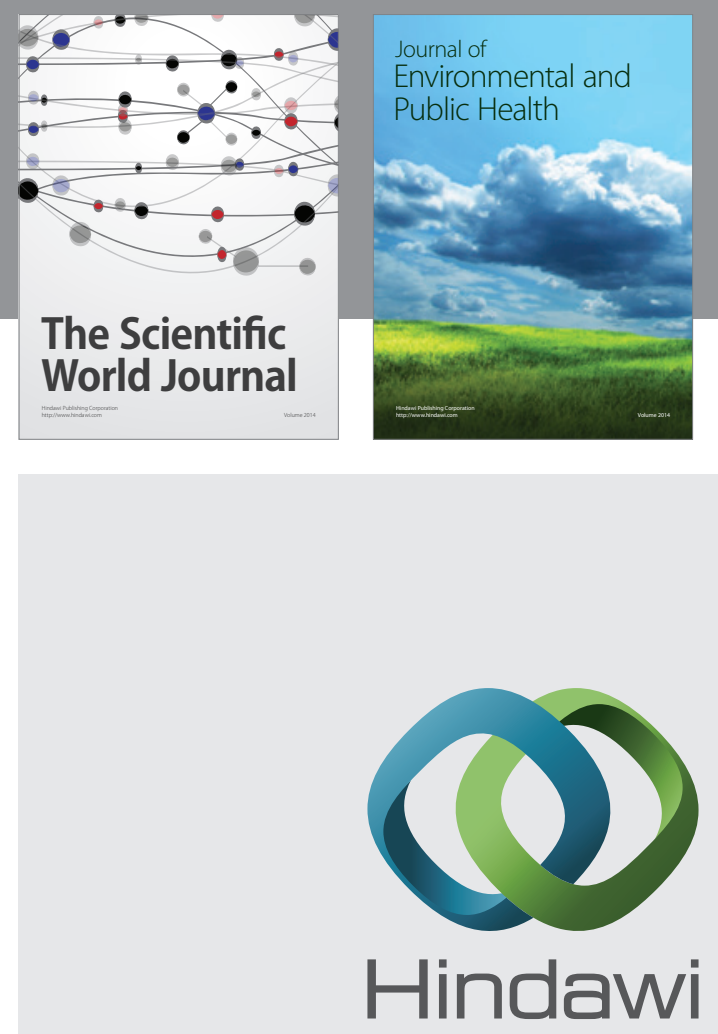

Submit your manuscripts at

http://www.hindawi.com
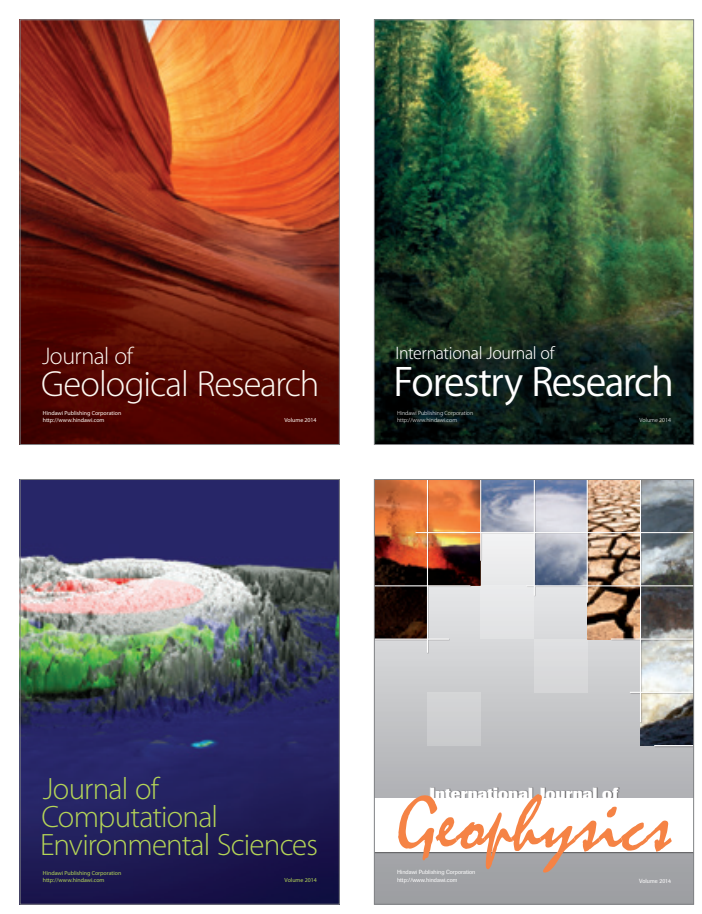
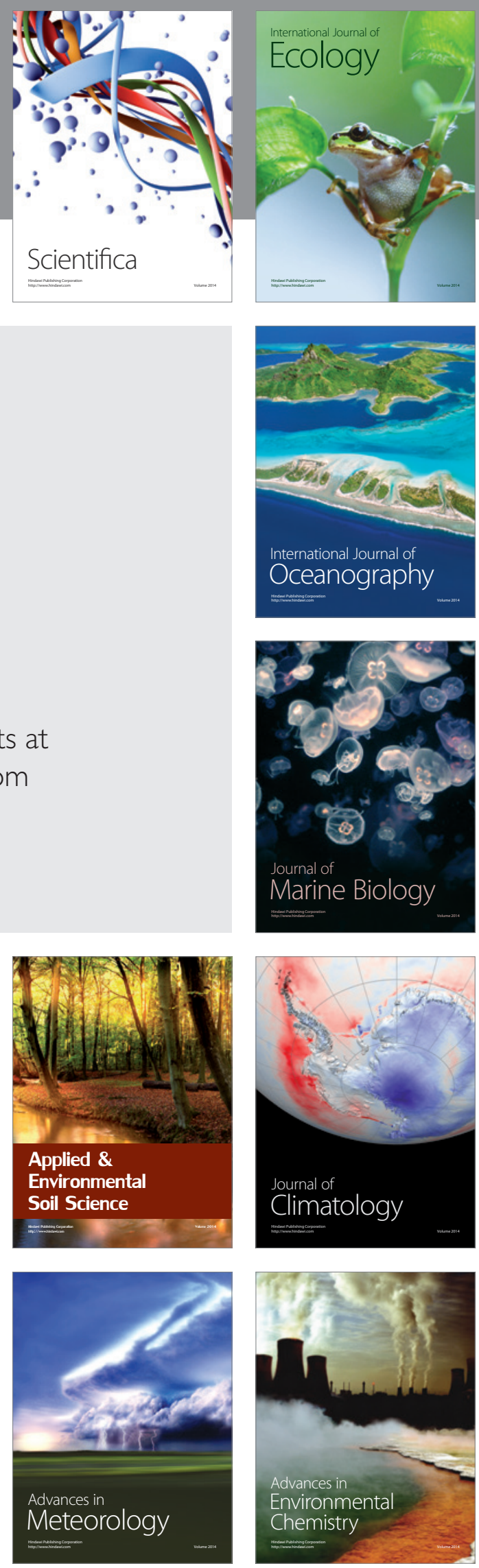